\title{
Comparison between bimatoprost and latanoprost-timolol fixed combination for efficacy and safety after switching patients from latanoprost
}

\author{
This article was published in the following Dove Press journal: \\ Clinical Ophthalmology \\ 7 August 2015 \\ Number of times this article has been viewed
}

\author{
Yuko Maruyama ${ }^{1,2}$ \\ Yoko Ikeda ${ }^{1,3}$ \\ Kazuhiko Mori' \\ Morio Ueno' \\ Haruna Yoshikawa' \\ Shigeru Kinoshita ${ }^{4}$ \\ 'Department of Ophthalmology, Kyoto \\ Prefectural University of Medicine, \\ ${ }^{2}$ Fukuchiyama City Hospital, ${ }^{3}$ Oike- \\ Ganka Ikeda Clinic, ${ }^{4}$ Department \\ of Frontier Medical Science and \\ Technology for Ophthalmology, Kyoto \\ Prefectural University of Medicine, \\ Kyoto, Japan
}

\begin{abstract}
Background: The purpose of this study was to prospectively evaluate and compare intraocular pressure (IOP) reduction efficacy and safety between bimatoprost and latanoprost-timolol fixed combination (LTFC) in Japanese patients with open-angle glaucoma.
\end{abstract}

Methods: In this prospective, randomized, non-masked study, after enrolling 70 eyes of 70 Japanese open-angle glaucoma patients who had used latanoprost monotherapy for more than 4 weeks, the subjects were randomly divided into a bimatoprost group or an LTFC group. Both groups were switched from latanoprost to bimatoprost or LTFC for 12 weeks. IOP, conjunctival injection score, corneal epitheliopathy score (area density classification; AD score), tear film break-up time, heart rate, and blood pressure were evaluated at 0,4 , and 12 weeks after switching. The paired $t$-test and Mann-Whitney $U$-test were used for the statistical analysis.

Results: After 13 of the 70 patients dropped out, 57 were analyzed for IOP reduction and safety. There was a significant decrease in mean IOP at 4 weeks compared with week 0 in both groups (both $P<0.0001$ ). Comparisons between the two groups showed no statistically significant differences. The conjunctival injection score was higher in the bimatoprost group than in the LTFC group at 12 weeks $(P=0.0091)$. There were no statistically significant differences between the two drugs in relation to AD score, tear film break-up time, heart rate, and blood pressure.

Conclusion: Bimatoprost and LTFC exhibited similar efficacy for reduction of IOP. Safety results indicated that only the conjunctival injection score at 12 weeks was higher in the bimatoprost group compared with the LTFC group.

Keywords: bimatoprost, latanoprost-timolol fixed combination, switching, prostaglandin analogs, open-angle glaucoma

\section{Introduction}

Glaucoma is one of the most devastating diseases worldwide, ${ }^{1,2}$ as is the main cause of blindness in adults. Studies have shown that intraocular pressure (IOP) is the most important risk factor for glaucoma and its progression. ${ }^{3,4}$ Since reduction of IOP is reportedly the most effective treatment for glaucoma, ${ }^{5,6}$ topical antiglaucoma medications are usually chosen as the primary treatment. Although topical $\beta$-blockers have been the primary drugs of choice in the past, prostaglandin analogs are now playing an important role in the medical treatment of the disease. In many cases, these new drugs have halted or reduced the progression of glaucoma., ${ }^{5,-9}$ The guidelines of the European Glaucoma Society and Japanese Glaucoma Society ${ }^{10}$ have recommended that if the first-choice monotherapy is not effective by itself, it is preferable to switch to another drug before giving consideration to any drug combination. Furthermore,
Correspondence: Kazuhiko Mori Department of Ophthalmology, Kyoto Prefectural University of Medicine, 465 Kajii-cho, Hirokoji-agaru, Kawaramachidori, Kamigyo-ku, Kyoto 602-084I, Japan Tel +8I 7525 I 5578

Fax +8I 7 525। 5663

Email kmori@koto.kpu-m.ac.jp 
when use of a prostaglandin analog alone cannot achieve glaucoma control, another prostaglandin or, perhaps, a second drug is added.

Bimatoprost $0.03 \%$ (LUMIGAN ${ }^{\circledR}$, Senju Pharmaceutical Co Ltd, Osaka, Japan) is a synthetic prostamide analog. It has been reported that bimatoprost acts on a prostamide-specific receptor that is different from normal prostaglandin receptors, which suggests a new mechanism of action. ${ }^{11}$ The IOPlowering properties of bimatoprost are achieved by enhancing both the trabecular meshwork and uveoscleral outflow without diminishing the production of aqueous humor. ${ }^{12}$ Several studies have reported that bimatoprost exhibits a greater IOPlowering effect than latanoprost $0.005 \%$ (Xalatan ${ }^{\circledR}$, Pfizer Inc, Tokyo, Japan). ${ }^{12-15}$ Among the possible drug combinations that can be used when adding a second drug, utilization of a prostaglandin analog with a $\beta$-blocker has been shown to be one of the most effective and widely prescribed combinations. ${ }^{16}$ In Japan, the fixed combination of latanoprost $0.005 \%$ and timolol maleate $0.5 \%$ (LTFC, Xalacom ${ }^{\circledR}$, Pfizer Inc) has recently become available. Among the several countries that have conducted trials for this drug, some have reported finding no significant advantage compared with latanoprost monotherapy, ${ }^{17,18}$ whereas others have reported that LTFC was as effective as concomitant administration of the individual components. ${ }^{19-21}$ However, to date, there have been no reported clinical trials on the IOP reduction efficacy and safety between bimatoprost and LTFC in Japanese patients with glaucoma.

The current study was designed to prospectively evaluate and compare the IOP reduction efficacy and safety using bimatoprost and LTFC in Japanese open-angle glaucoma patients who had not controlled by latanoprost monotherapy.

\section{Subjects and methods}

In this prospective, randomized, non-masked study, we examined 70 eyes of 70 Japanese open-angle glaucoma patients (42 females and 28 males, mean age 66.9 \pm 12.9 years) who had received latanoprost monotherapy for more than 4 weeks in at least one eye. Patients were randomly divided into a bimatoprost group or an LTFC group. Both groups were switched from latanoprost to either bimatoprost or LTFC for 12 weeks. This study was approved by the institutional review board of Kyoto Prefectural University of Medicine, Kyoto, Japan. All experimental procedures were conducted in accordance with the tenets set forth in the Declaration of Helsinki. Written informed consent was obtained from all patients. Patients who were treated by latanoprost monotherapy at the Kyoto Prefectural University of Medicine and Oike-Ikeda Eye Clinic and could not achieve IOP control or had progressive glaucomatous changes in their visual field were enrolled in the study between 2011 and 2013. All subjects involved in the study were Japanese. The diagnostic criteria for normal-tension glaucoma (NTG) were: (1) normal iridocorneal open angle, (2) no evidence of high IOP (IOP $\leq 21 \mathrm{mmHg}$ ), (3) glaucomatous changes in the visual field with optic nerve cupping, and (4) absence of other optic neuropathies. For the diagnosis of primary open-angle glaucoma (POAG), while numbers (1), (3), and (4) of the earlier listed criteria were the same, patients had to have a maximum IOP $>21 \mathrm{mmHg}$. All NTG and POAG diagnoses were made according to the guidelines of the Japan Glaucoma Society and European Glaucoma Society. Patients with a past history of other treatments, such as laser surgery or glaucoma surgery, were excluded from the study. We also excluded patients who had diseases that are not suitable for $\beta$-blocker eyedrops, such as asthma, hyperreactive airway disease, and heart disease.

In all patients, IOP, conjunctival injection score (grade: 0-3), corneal epitheliopathy score (area density classification; AD score), tear film break-up time (BUT), systolic and diastolic blood pressure (BP), and heart rate (HR) were evaluated at $0,4 \pm 1$, and $12 \pm 2$ weeks after switching. Since each patient came to the hospital at the same time for these three measurements, we were able to measure all parameters at the same time of day. IOP was measured by a Goldmann applanation tonometer. If both eyes were available, we used the right eye data only. At every visit, the mean BUT score was calculated from three measurements determined using a stopwatch, and conjunctival status were evaluated from slit-lamp images. Three glaucoma specialists conducted the study.

The following parameters were compared between the two groups: mean IOP values, mean IOP changes, injection score, AD score, BUT, HR, systolic BP, and diastolic BP. Mean IOP changes were compared between the two groups at different time points.

\section{Statistical analysis}

Fisher's exact test was used to compare the number of patients in the two groups who had responded to therapy and exhibited an IOP reduction. We also compared the ratio of patients in the two groups who exhibited no IOP changes, increased IOP, or reduced IOP. Patients who had changes that were within a $\pm 10 \%$ IOP reduction were classified as exhibiting no changes. The paired Student's $t$-test was used to compare parameter values within each of the two groups, while the 
Mann-Whitney $U$-test was used for statistical comparison of values between the two groups. A $P$-value of $<0.05$ was considered to be statistically significant. These analyses were performed using scientific biostatistics graphing software (GraphPad Prism ${ }^{\circledR}$ version 6.0.3, GraphPad Software Inc, La Jolla, CA, USA). For the sample size calculations, the significance level was set to $5 \%$ and the power to $80 \%$. The 35-patients-per-group number was calculated for a $\Delta$ of $1.7 \mathrm{mmHg}$ and standard deviation of $2.5 \mathrm{mmHg}$.

\section{Results}

\section{Patient characteristics}

Thirteen of the 70 patients dropped out of the study, resulting in 57 ( 33 females and 24 males, mean age $64.7 \pm 12.9$ years) being available for analysis of IOP reduction and safety. The primary reason why patients dropped out of the study was poor compliance (five patients in the LTFC group). Side effects led to four patients in the bimatoprost group (itching and blurred vision) and two patients in the LTFC group (coughing and palpitations, pain in the eyes) also dropping out of the study. Another two patients were withdrawn because they were discovered to be taking oral steroid medications.

Of the 57 analyzed patients, 30 were assigned to the bimatoprost group (19 females and eleven males, mean age $66.4 \pm 12.4$ years) and 27 were assigned to the LTFC group (14 females and 13 males, mean age $62.9 \pm 13.5$ years). The bimatoprost group consisted of five POAG patients and 22 NTG patients, while the LTFC group consisted of six POAG patients and 24 NTG patients. There were no statistically significant differences found between groups for mean age $(P=0.3001)$ or $\operatorname{sex}(P=0.4295)$ ratio.

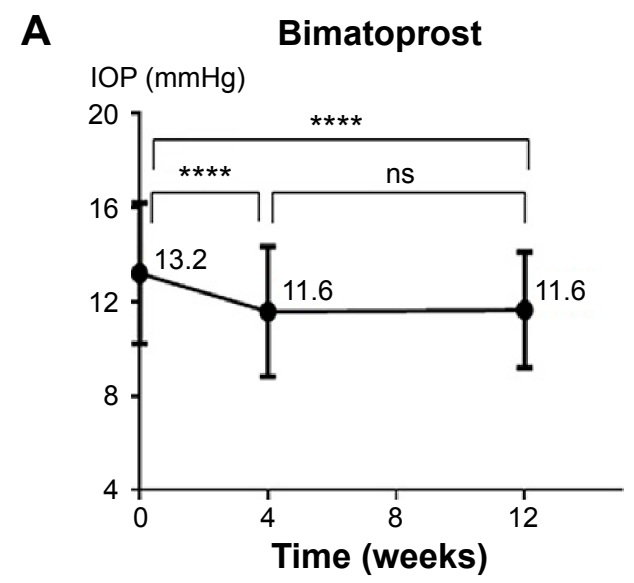

\section{Mean IOP change in the bimatoprost and LTFC groups}

At 0,4 , and 12 weeks, the mean IOPs of the bimatoprost (30 eyes) and LTFC (27 eyes) groups were 13.2, 11.6, and 11.6 $\mathrm{mmHg}$, and $13.3,11.5$, and $11.6 \mathrm{mmHg}$, respectively. In both groups, there was already a significant decrease in mean IOP at 4 weeks compared with week $0(P<0.0001$ in both groups; Figure 1A and B). There were no IOP differences at 12 weeks compared with the values at 4 weeks in both groups ( $P=0.8498$ for the bimatoprost group and $P=0.8427$ for the LTFC group; Figure 1A and B). IOP comparisons between the two groups additionally showed no significant differences at 4 or 12 weeks $(P=0.6743$ and $P=0.9143$; Table 1 , Figure 2).

We also compared the two groups for the ratio of patients with no IOP changes, with an increased IOP, and with a reduced IOP. There were no significant differences in any of the ratios between any of the groups analyzed (Table 2).

\section{Side effects observed in the LTFC and bimatoprost groups}

The conjunctival injection scores were $0.6 \pm 0.5,0.9 \pm 0.7$, and $1.2 \pm 0.8$ for the bimatoprost group and $0.7 \pm 0.5,0.7 \pm 0.6$, and $0.6 \pm 0.5$ for the LTFC group at 0,4 , and 12 weeks, respectively. The conjunctival injection score at 12 weeks was higher in the bimatoprost group vs the LTFC group $(P=0.0091$; Table 3$)$. There were no significant differences in either of the groups for the conjunctival injection score at 4 weeks ( $P=0.4032$; Table 3$)$.

The corneal AD scores (total score of area and density grade) at baseline were $1.9 \pm 1.5$ for the bimatoprost group and $1.6 \pm 1.4$ for the LTFC group. The scores were $1.5 \pm 1.4$ and

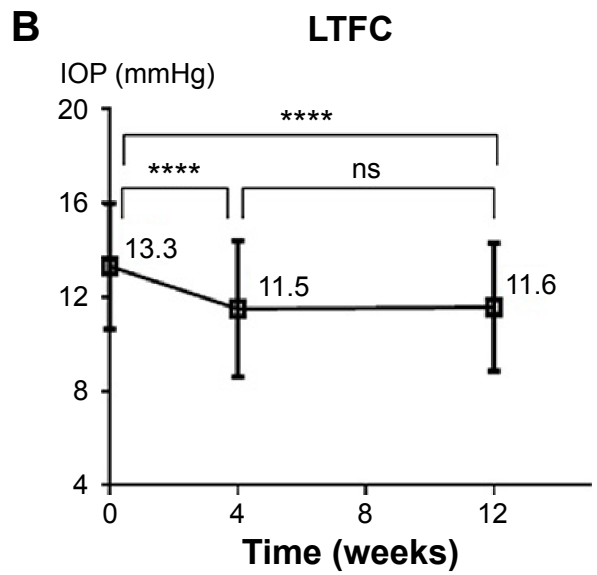

Figure I Mean IOP change from baseline (week 0 ) in the bimatoprost and LTFC groups.

Notes: Data are given as the mean \pm standard deviation. $* * * * P<0.0001$. Mean IOP change from baseline (week 0$)$ in the bimatoprost group $(\mathbf{A})$ and the LTFC group (B). In both groups, IOP lowering was observed from week 0 to week 4, and then remained constant from week 4 through week 12.

Abbreviations: IOP, intraocular pressure; LTFC, latanoprost-timolol fixed combination; ns, non-significant. 
Table I Intraocular pressure levels in the LTFC and bimatoprost groups at baseline, week 4 , and week 12

\begin{tabular}{llll}
\hline Assessment & LTFC & Bimatoprost & P-value \\
\hline Baseline $(\mathrm{mmHg})$ & $13.3 \pm 2.7$ & $13.2 \pm 3.0$ & 0.72 \\
Week $4(\mathrm{mmHg})$ & $1 \mathrm{I} .5 \pm 2.9$ & $1 \mathrm{I} .6 \pm 2.7$ & 0.67 \\
Week $12(\mathrm{mmHg})$ & $1 \mathrm{I} .6 \pm 2.7$ & $1 \mathrm{I} .6 \pm 2.5$ & 0.91 \\
\hline
\end{tabular}

Note: Data are given as the mean \pm standard deviation.

Abbreviation: LTFC, latanoprost-timolol fixed combination.

1.6 \pm 1.4 for the bimatoprost group and $1.6 \pm 1.4$ and $1.7 \pm 1.4$ for the LTFC group at 4 and 12 weeks, respectively. At baseline, BUT was $6.0 \pm 4.4$ seconds in the bimatoprost group and was $5.2 \pm 4.0$ seconds in the LTFC group. The values were 6.0 \pm 4.7 and 5.4 \pm 4.3 seconds in the bimatoprost group and 5.0 \pm 4.5 and 5.2 \pm 3.9 seconds in the LTFC group at 4 and 12 weeks, respectively. There were no significant differences between the two drugs in relation to AD score or BUT (Table 3).

At 0,4 , and 12 weeks, the mean systolic/diastolic BP in the bimatoprost group and LTFC group was 127/73, 127/74, and $129 / 75 \mathrm{mmHg}$, respectively, and 130/75, 128/76, and $129 / 74 \mathrm{mmHg}$. There were no significant differences in systolic BP or diastolic BP at 4 and 12 weeks compared with the values at week 0 in either group. BP comparisons between the two groups also showed no significant differences at 4 or 12 weeks (Table 3 ).

At 0,4 , and 12 weeks, mean HR in the bimatoprost and LTFC groups was 80, 79, and 77 beats per minute, respectively, and 77,76 , and 77 beats per minute. There were no significant differences in HR at 4 and 12 weeks compared with week 0 in either group. In addition, there were no significant differences in HR comparisons between

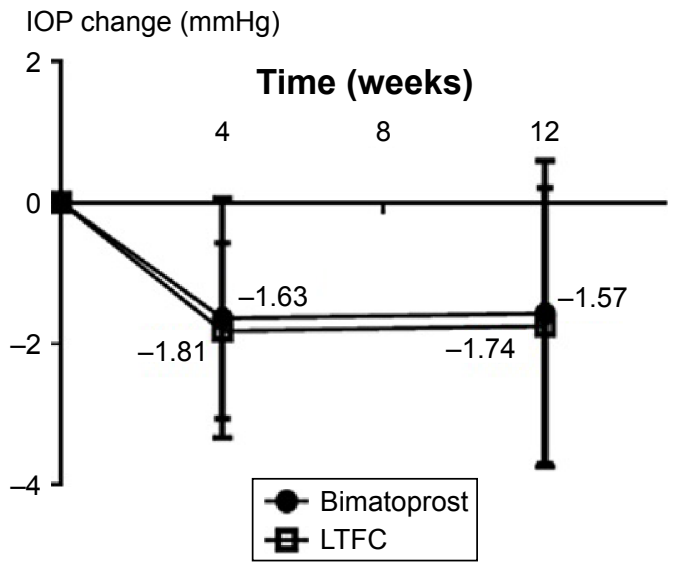

Figure 2 Mean IOP change from baseline (week 0$)$. No significant difference between the two groups was observed at week $4(P=0.4052)$ or at week $12(P=0.6968)$. Note: Data are given as the mean \pm standard deviation.

Abbreviations: IOP, intraocular pressure; LTFC, latanoprost-timolol fixed combination.
Table 2 Percentage of patients whose mean IOP increased, decreased, or stayed the same compared with baseline after switching from latanoprost monotherapy at week 12

\begin{tabular}{llll}
\hline & $\begin{array}{l}\text { LTFC } \\
(\mathbf{n}=\mathbf{2 7})\end{array}$ & $\begin{array}{l}\text { Bimatoprost } \\
(\mathbf{n}=\mathbf{3 0})\end{array}$ & P-value \\
\hline$>10 \%$ IOP increase & $\mathrm{I}(3.7 \%)$ & $\mathrm{I}(3.3 \%)$ & 1.00 \\
$\pm 10 \%$ IOP change & $10(37 \%)$ & $13(43.3 \%)$ & 0.79 \\
$10 \%<$ IOP reduction $\leq 20 \%$ & $7(25.9 \%)$ & $9(30 \%)$ & 0.78 \\
$20 \%<$ IOP reduction $\leq 30 \%$ & $6(22.2 \%)$ & $4(13.3 \%)$ & 0.49 \\
$>30 \%$ IOP reduction & $3(11.1 \%)$ & $3(10 \%)$ & 1.00 \\
\hline
\end{tabular}

Abbreviations: LTFC, latanoprost-timolol fixed combination; IOP, intraocular pressure.

the two groups at 4 and 12 weeks $(P=0.3719$ and $P=0.8803$; Table 3).

\section{Discussion}

In this randomized clinical study, 70 Japanese open-angle glaucoma patients uncontrolled IOP being treated by latanoprost only were changed to a new therapy of either bimatoprost or LTFC. While bimatoprost and LTFC have previously been reported to have the same efficacy for lowering IOP in some studies, ${ }^{22-24}$ another study reported that LTFC was superior to bimatoprost in reducing IOP. ${ }^{25}$ Our study, which is the first randomized prospective clinical trial of these two treatments in the Japanese population, showed that both treatments were effective in controlling IOP starting from baseline. It has also been reported that bimatoprost has a greater IOP-lowering effect than latanoprost, ${ }^{12-15}$ and that LTFC reduces the IOP levels to a greater degree than latanoprost monotherapy ${ }^{26-30}$ in both the Japanese population and in other races. We found similar results in our current study.

However, some patients in the current study did not exhibit any IOP reduction after being changed to either bimatoprost or LTFC. Since we only enrolled patients who responded to latanoprost, it is possible that patients who exhibited no reduction in their IOP after being changed to LTFC could have been nonresponders or poor responders to $\beta$-blockers. It has also been reported that LTFC was more effective than latanoprost monotherapy, but less efficacious than unfixed combinations of latanoprost-timolol. ${ }^{31}$ In these patients, the $\beta$-blocker had been previously used twice a day while LTFC was used only once a day, so LTFC might be less effective if we used latanoprost once a day plus $\beta$-blockers twice a day.

On the other hand, there were also 13 patients (43.3\%) who did not exhibit a reduced IOP after being changed to bimatoprost, indicating that the effect of bimatoprost is almost equal to that of latanoprost. One patient $(3.3 \%)$ who exhibited an increased IOP after being changed to bimatoprost was thought to be a nonresponder to bimatoprost. 
Table 3 Side effects in the LTFC and bimatoprost groups at baseline, week 4, and week 12

\begin{tabular}{|c|c|c|c|c|c|c|c|c|c|}
\hline & \multicolumn{3}{|c|}{ Baseline } & \multicolumn{3}{|c|}{ Week 4} & \multicolumn{3}{|c|}{ Week I2 } \\
\hline & LTFC & Bimatoprost & $P$-value & LTFC & Bimatoprost & $P$-value & LTFC & Bimatoprost & $P$-value \\
\hline Injection & $0.7 \pm 0.5$ & $0.6 \pm 0.5$ & 0.50 & $0.7 \pm 0.6$ & $0.9 \pm 0.7$ & 0.40 & $0.6 \pm 0.5$ & $1.2 \pm 0.8$ & $0.0091 * *$ \\
\hline$A D$ score & $1.6 \pm 1.4$ & $1.9 \pm 1.5$ & 0.63 & $1.6 \pm 1.4$ & $1.5 \pm 1.4$ & 0.70 & $1.7 \pm 1.4$ & $1.6 \pm 1.4$ & 0.82 \\
\hline BUT (seconds) & $5.2 \pm 4.0$ & $6.0 \pm 4.4$ & 0.57 & $5.0 \pm 4.5$ & $6.0 \pm 4.7$ & 0.42 & $5.2 \pm 3.9$ & $5.4 \pm 4.3$ & 0.82 \\
\hline HR (beats per minute) & $77 \pm 13$ & $80 \pm 12$ & 0.21 & $76 \pm 13$ & $79 \pm 11$ & 0.37 & $77 \pm 15$ & $77 \pm 10$ & 0.88 \\
\hline Systolic BP (mmHg) & $130 \pm 23$ & $127 \pm 23$ & 0.40 & $128 \pm 24$ & $127 \pm 24$ & 0.83 & $129 \pm 23$ & $129 \pm 23$ & 0.91 \\
\hline Diastolic BP (mmHg) & $75 \pm 15$ & $73 \pm 13$ & 0.29 & $76 \pm 15$ & $74 \pm 13$ & 0.30 & $74 \pm 15$ & $75 \pm 13$ & 0.47 \\
\hline
\end{tabular}

Notes: Data are given as the mean \pm standard deviation. $* * P<0.01$.

Abbreviations: LTFC, latanoprost-timolol fixed combination; AD, area density classification; BUT, tear film break-up time; HR, heart rate.

The IOP-lowering effect of bimatoprost was reported to be equal to that of latanoprost in a previous report. ${ }^{32} \mathrm{We}$ found similar results in some of our patients in the current study. Thus, the IOP-lowering effect of bimatoprost could differ from patient to patient. Some patients did not exhibit a reduced IOP after switching to bimatoprost or LTFC; however, most of the patients exhibited minor IOP reduction. Moreover, IOP was considerably reduced in some patients after switching to bimatoprost and LTFC, so we found significant differences in IOP after switching from latanoprost.

While it appears that bimatoprost has great potential with regard to its IOP-lowering effect, it has been reported to cause more conjunctival hyperemia than has been seen in patients treated with latanoprost $\mathrm{t}^{15,33}$ or LTFC. ${ }^{23,24}$ In our study, we found that the conjunctival injection score at 12 weeks was higher in the bimatoprost group vs the LTFC group, which mirrors the results of the previous reports.

Since LTFC contains $\beta$-blocker eyedrops, the possibility exists that it could affect both HR and BP. $\beta$-blocker eyedrops can be directly absorbed into the systemic circulation, which occurs mainly through the nasopharyngeal mucosa. However, this has yet to be definitively clarified, as some previous papers have reported that eyedrops containing a $\beta$-blocker affected the HR but not the $\mathrm{BP},{ }^{25,34}$ while other studies have reported that these eyedrops did not affect either HR or BP. ${ }^{35,36}$ Our current study could not find any differences in HR or BP between the bimatoprost and LTFC groups. HR and BP changes can also be affected by several other parameters, such as age and duration of $\beta$-blocker eyedrop use. Since $\beta$-blocker eyedrops cannot be used in patients with heart or pulmonary disease, we excluded these patients from our study. Thus, this exclusion could have affected our results. It has recently been reported that no differences were found in 24-hour IOP, systolic BP, or diastolic BP between latanoprost and bimatoprost in NTG patients. ${ }^{37}$ In that study, they also investigated diastolic ocular perfusion pressure (DOPP), and the mean 24-hour DOPP for latanoprost was increased from baseline for latanoprost, but not for bimatoprost. In this study, we did not investigate DOPP; however, it would be interesting to investigate.

It has also been reported that $\beta$-blocker eyedrops can have adverse effects on the ocular surface epithelium or tear function. ${ }^{38-40}$ Our current study could not find any differences in either the AD scores or the BUT. LTFC eyedrops contain a $\beta$-blocker (timolol). Since we used LTFC once a day and timolol is usually used twice a day, this could have affected our results. In a previous report, significant differences were found at 20 weeks after starting $\beta$-blocker eyedrops. ${ }^{29} \mathrm{We}$ only observed our patients for 12 weeks, and if we had continued our investigations for a longer time period, we may have found differences between the two groups.

The results of the current study indicated no differences in IOP reduction in the bimatoprost and LTFC groups, suggesting that both treatments can be considered for use in patients with uncontrolled IOP after latanoprost monotherapy. However, since both types of eyedrop are associated with various side effects, the type of eyedrop used needs to be carefully chosen in accordance with each individual case. Furthermore, as patients with pulmonary or heart disease can encounter severe side effects after administration of $\beta$-blocker eyedrops, the past history should be carefully examined before choosing the type of eyedrop to use.

Some patients are not aware that heart or pulmonary disease is a contraindication to $\beta$-blocker use when the symptoms of those patients are mild. Moreover, as the possibility exists that these diseases can emerge with age, it should always be considered that there is a possible risk of side effects in patients even when they report that they do not have these diseases. Moreover, since there is an increase in the percentage of patients with pulmonary or heart disease with age, it might be best to choose bimatoprost rather than LTFC when treating elderly patients.

Out of the total of 70 patients, 13 patients dropped out before finishing this study. Reasons for dropping out included 
not being able to visit the hospital at the appointed time or because they found it impossible to use the eyedrops according to the set schedule. The fact that so many subjects dropped out raises the possibility that compliance issues could be a major factor that needs to be taken into consideration when setting up treatments. We also found that side effects led to four patients in the bimatoprost group (itching and blurred vision) and two patients in the LTFC group (coughing and palpitations, pain in their eyes) dropping out of the study. Even though the number of patients who dropped out due to side effects was larger in the bimatoprost group than in the LTFC group in this study, bimatoprost was a better treatment for some patients because bimatoprost did not contain a $\beta$-blocker and was able to effectively control their IOP.

Since more conjunctival injections are required for bimatoprost vs LTFC, cosmetic problems are of particular concern in women and young people, and it is recommended that LTFC be used in patients who express a concern about these potential cosmetic problems. Therefore, when choosing eyedrops to treat patients, one must carefully consider not only the patient's age, sex, and physical condition, but also the degree of compliance expected.

It should be noted that this study did have some limitations. First, we only compared the efficacies of bimatoprost and LTFC in patients who had been previously treated with latanoprost. Furthermore, this study did not simply compare the IOP-lowering effects of the two drugs.

Another limitation was that there were four times as many NTG patients vs POAG patients in this study. Using a Japanese population, the findings of a previous study revealed that there were many more NTG patients than POAG patients. ${ }^{41}$ We had to further decrease the IOP in the NTG patients when one drug could not halt or reduce the progression of visual field loss if the IOP was in the low teen values because the baseline was low. In a fixed combination study, it was reported that there was a strong linear relationship between the mean baseline IOP and the treatment-induced mean reduction in IOP. ${ }^{42}$ In that study, since most of the patients were NTG patients with the characteristic Japanese glaucoma type, no significant differences were found between the two groups because the IOP reduction was low due to the low baseline IOP. We plan on enrolling more POAG patients to compare the IOP reduction between bimatoprost and LTFC in POAG patients in a future investigation.

An additional limitation was that there was no washout period when we switched from latanoprost to bimatoprost or LTFC. In this study, some patients' visual field loss progressed with the disease, so there was not enough time to have a washout period. However, we evaluated IOP and other parameters at 12 weeks after switching from latanoprost, which should be a sufficient amount of time to eliminate the influence of latanoprost.

A further limitation was that although we compared IOP and BP at the same time in each patient, we were not able to measure IOP and BP at the same time in all patients. Further, we had compliance issues. There might be a possibility that the IOP reduction after switching to bimatoprost or LTFC was partly due to the fact that patient compliance was better after switching from latanoprost, ie, the Hawthorne effect.

We also had additional limitations. Although this study was randomized, it was not masked, and it was conducted not only in a university hospital but also in a private clinic, so it was difficult to prescribe eyedrops in a masked manner. Another limitation was that although 70 patients were enrolled, only 57 patients were ultimately analyzed due to the number of dropouts. In the future, we plan to enroll a greater number of patients for analysis. Finally, we only observed patients for 12 weeks in the current study. Thus, further investigations with a longer follow-up period will need to be undertaken.

\section{Conclusion}

Bimatoprost and LTFC have similar efficacy for the reduction of IOP. Safety comparisons between the two drugs showed that only the conjunctival injection score at 12 weeks was higher in the bimatoprost group vs the LTFC group.

\section{Disclosure}

YI, KM and MU have received financial support from Senju Pharmaceutical Co Ltd. The authors have no other conflicts of interest in this work.

\section{References}

1. Resnikoff S, Pascolini D, Etya'ale D, et al. Global data on visual impairment in the year 2002. Bull World Health Organ. 2004;82(11): 844-851.

2. Quigley HA, Broman AT. The number of people with glaucoma worldwide in 2010 and 2020. Br J Ophthalmol. 2006;90(3):262-267.

3. Leske MC, Connell AM, Wu SY, Hyman LG, Schachat AP. Risk factors for open-angle glaucoma. The Barbados Eye Study. Arch Ophthalmol. 1995;113(7):918-924.

4. Coleman AL, Miglior S. Risk factors for glaucoma onset and progression. Surv Ophthalmol. 2008;53 Suppl 1:S3-S10.

5. Kass MA, Heuer DK, Higginbotham EJ, et al. The Ocular Hypertension Treatment Study: a randomized trial determines that topical ocular hypotensive medication delays or prevents the onset of primary openangle glaucoma. Arch Ophthalmol. 2002;120(6):701-713.

6. Heijl A, Leske MC, Bengtsson B, Hussein M. Measuring visual field progression in the Early Manifest Glaucoma Trial. Acta Ophthalmol Scand. 2003;81(3):286-293. 
7. Lichter PR, Musch DC, Gillespie BW, et al. Interim clinical outcomes in the Collaborative Initial Glaucoma Treatment Study comparing initial treatment randomized to medications or surgery. Ophthalmology. 2001;108(11):1943-1953.

8. [AGIS Investigators]. The Advanced Glaucoma Intervention Study (AGIS): 9. Comparison of glaucoma outcomes in black and white patients within treatment groups. Am J Ophthalmol. 2001;132(3):311-320.

9. Heijl A, Leske MC, Bengtsson B, Hyman L, Hussein M. Reduction of intraocular pressure and glaucoma progression: results from the Early Manifest Glaucoma Trial. Arch Ophthalmol. 2002;120(10):1268-1279.

10. The Japan Glaucoma Society Guidelines for Glaucoma (3rd Edition). Nihon Ganka Gakkai Zasshi. 2012;116(1):3-46. Japanese.

11. Sharif NA, Williams GW, Kelly CR. Bimatoprost and its free acid are prostaglandin FP receptor agonists. Eur J Pharmacol. 2001;432(2-3): 211-213.

12. Brubaker RF. Mechanism of action of bimatoprost (Lumigan). Surv Ophthalmol. 2001;45 Suppl 4:S347-S351.

13. Gandolfi S, Simmons ST, Sturm R, Chen K, VanDenburgh AM. Three-month comparison of bimatoprost and latanoprost in patients with glaucoma and ocular hypertension. Adv Ther. 2001;18(3): $110-121$

14. Higginbotham EJ, Schuman JS, Goldberg I, et al. One-year, randomized study comparing bimatoprost and timolol in glaucoma and ocular hypertension. Arch Ophthalmol. 2002;120(10):1286-1293.

15. Sato S, Hirooka K, Baba T, et al. Efficacy and safety of switching from topical latanoprost to bimatoprost in patients with normal-tension glaucoma. J Ocul Pharmacol Ther. 2011;27(5):499-502.

16. Ventura MP, Saheb NE, Solari HP, et al. Cost considerations of the new fixed combinations for glaucoma medical therapy. J Clin Pharm Ther. 2005;30(3):251-254.

17. Higginbotham EJ, Feldman R, Stiles M, Dubiner H. Latanoprost and timolol combination therapy vs monotherapy: one-year randomized trial. Arch Ophthalmol. 2002;120(7):915-922.

18. Magacho L, Reis R, Shetty RK, Santos LC, Avila MP. Efficacy of latanoprost or fixed-combination latanoprost-timolol in patients switched from a combination of timolol and a nonprostaglandin medication. Ophthalmology. 2006;113(3):442-445.

19. Konstas AG, Banyai L, Blask KD, et al. Intraocular pressure and safety in glaucoma patients switching to latanoprost/timolol maleate fixed combination from mono- and adjunctive therapies. $J$ Ocul Pharmacol Ther. 2004;20(5):375-382.

20. Diestelhorst M, Larsson LI. A 12-week, randomized, double-masked, multicenter study of the fixed combination of latanoprost and timolol in the evening versus the individual components. Ophthalmology. 2006;113(1):70-76.

21. Inoue K, Okayam R, Higa R, et al. Ocular hypotensive effects and safety over 3 months of switching from an unfixed combination to latanoprost $0.005 \% /$ timolol maleate $0.5 \%$ fixed combination. J Ocul Pharmacol Ther. 2011;27(6):581-587.

22. Manni G, Centofanti M, Parravano M, Oddone F, Bucci MG. A 6-month randomized clinical trial of bimatoprost $0.03 \%$ versus the association of timolol $0.5 \%$ and latanoprost $0.005 \%$ in glaucomatous patients. Graefes Arch Clin Exp Ophthalmol. 2004;242(9):767-770.

23. Rossetti L, Karabatsas CH, Topouzis F, et al. Comparison of the effects of bimatoprost and a fixed combination of latanoprost and timolol on circadian intraocular pressure. Ophthalmology. 2007;114(12): 2244-2251.

24. Mesci C, Aydin N, Erbil HH. Twenty-four-hour intraocular pressure control with latanoprost-timolol-fixed combination versus bimatoprost in patients who switched from timolol. J Glaucoma. 2011;20(8):477-481.

25. Facio AC, Reis AS, Vidal KS, et al. A comparison of bimatoprost $0.03 \%$ versus the fixed-combination of latanoprost $0.005 \%$ and timolol $0.5 \%$ in adult patients with elevated intraocular pressure: an eight-week, randomized, open-label trial. J Ocul Pharmacol Ther. 2009;25(5):447-451
26. Inoue $\mathrm{K}$, Fujimoto T, Higa R, et al. Efficacy and safety of a switch to latanoprost $0.005 \%+$ timolol maleate $0.5 \%$ fixed combination eyedrops from latanoprost $0.005 \%$ monotherapy. Clin Ophthalmol. 2012;6:771-775.

27. Varma R, Hwang LJ, Grunden JW, Bean GW. Using diurnal intraocular pressure fluctuation to assess the efficacy of fixed-combination latanoprost/timolol versus latanoprost or timolol monotherapy. $\mathrm{Br} \mathrm{J}$ Ophthalmol. 2010;94(1):80-84.

28. Palmberg P, Kim EE, Kwok KK, Tressler CS. A 12-week, randomized, double-masked study of fixed combination latanoprost/timolol versus latanoprost or timolol monotherapy. Eur J Ophthalmol. 2010;20(4):708-718.

29. Lazaridou MN, Montgomery DM, Ho WO, Jaberoo D. Changes in intraocular pressure following a switch from latanoprost monotherapy to latanoprost/timolol fixed combination therapy in patients with primary open-angle glaucoma or ocular hypertension: results from a clinical practice database. Curr Med Res Opin. 2008;24(10):2725-2728.

30. Konstas AG, Boboridis K, Tzetzi D, et al. Twenty-four-hour control with latanoprost-timolol-fixed combination therapy vs latanoprost therapy. Arch Ophthalmol. 2005;123(7):898-902.

31. Quaranta L, Biagioli E, Riva I, et al. Prostaglandin analogs and timololfixed versus unfixed combinations or monotherapy for open-angle glaucoma: a systematic review and meta-analysis. J Ocul Pharmacol Ther. 2013;29(4):382-389.

32. Huang HL, Sun XH, Xiao M. [Comparison of intraocular pressure reducing effects of three prostaglandin eyedrops in open-angle glaucoma]. Zhonghua Yan Ke Za Zhi. 2011;47(2):109-113. Chinese.

33. Casson RJ, Liu L, Graham SL, et al. Efficacy and safety of bimatoprost as replacement for latanoprost in patients with glaucoma or ocular hypertension: a uniocular switch study. J Glaucoma. 2009;18(8):582-588.

34. Kashiwagi K. Efficacy and safety of switching to travoprost/timolol fixed-combination therapy from latanoprost monotherapy. Jpn J Ophthalmol. 2012;56(4):339-345.

35. Chiselita D, Antohi I, Medvichi R, Danielescu C. [Comparative analysis of the efficacy and safety of latanoprost, travoprost and the fixed combination timolol-dorzolamide; a prospective, randomized, masked, cross-over design study]. Oftalmologia. 2005;49(3):39-45. Romanian.

36. Moisseiev E, Kurtz S, Lazar M, Shemesh G. Intraocular pressure reduction using a fixed combination of timolol maleate $0.5 \%$ and brimonidine tartrate $0.2 \%$ administered three times daily. Clin Ophthalmol. 2013;7:1269-1273.

37. Quaranta L, Pizzolante T, Riva I, et al. Twenty-four-hour intraocular pressure and blood pressure levels with bimatoprost versus latanoprost in patients with normal-tension glaucoma. Br J Ophthalmol. 2008;92(9):1227-1231.

38. Shimazaki J, Hanada K, Yagi Y, et al. Changes in ocular surface caused by antiglaucomatous eyedrops: prospective, randomised study for the comparison of $0.5 \%$ timolol v $0.12 \%$ unoprostone. $\mathrm{Br} J$ Ophthalmol. 2000;84(11):1250-1254.

39. Ohtsuki M, Yokoi N, Mori K, et al. [Adverse effects of beta-blocker eye drops on the ocular surface]. Nihon Ganka Gakkai Zasshi. 2001; 105(3):149-154.

40. Valente C, Iester M, Corsi E, Rolando M. Symptoms and signs of tear film dysfunction in glaucomatous patients. J Ocul Pharmacol Ther. 2011;27(3):281-285.

41. Iwase A, Suzuki Y, Araie M, et al. The prevalence of primary openangle glaucoma in Japanese: the Tajimi Study. Ophthalmology. 2004; 111(9):1641-1648.

42. Hollo G, Vuorinen J, Tuominen J, et al. Fixed-dose combination of tafluprost and timolol in the treatment of open-angle glaucoma and ocular hypertension: comparison with other fixed-combination products. Adv Ther. 2014;31(9):932-944. 


\section{Publish your work in this journal}

Clinical Ophthalmology is an international, peer-reviewed journal covering all subspecialties within ophthalmology. Key topics include: Optometry; Visual science; Pharmacology and drug therapy in eye diseases; Basic Sciences; Primary and Secondary eye care; Patient Safety and Quality of Care Improvements. This journal is indexed on

Submit your manuscript here: http://www.dovepress.com/clinical-ophthalmology-journal
PubMed Central and CAS, and is the official journal of The Society of Clinical Ophthalmology (SCO). The manuscript management system is completely online and includes a very quick and fair peer-review system, which is all easy to use. Visit http://www.dovepress.com/ testimonials.php to read real quotes from published authors. 